\title{
Artigo/Article
}

\section{Prevalência de anticorpos antileishmania spp em cães de Garanhuns, Agreste de Pernambuco}

\author{
Prevalence of anti-Leishmania spp antibodies in dogs from Garanhuns, in the middle scrub \\ zone (Agreste) of Pernambuco
}

\begin{abstract}
Jessica Maria Leite dos Santos ${ }^{1}$, Filipe Dantas-Torres ${ }^{2,3}$, Marcos Renato Franzosi Mattos ${ }^{1}$, Felipe Ragner Lima Lino ${ }^{1}$, Lílian Sabrina Silvestre Andrade ${ }^{4}$, Rute Chamié Alves de Souza ${ }^{1}$, Fábio Luiz da Cunha Brito ${ }^{1}$, Maria Edileuza Felinto de Brito², Sinval Pinto Brandão-Filho² e Lucilene Simões-Mattos ${ }^{1}$
\end{abstract}

\section{RESUMO}

Introdução: Desconhecida a realidade da leishmaniose visceral canina em Garanhuns, objetivou-se investigar a ocorrência de anticorpos antileishmania spp em cães domiciliados e semidomiciliados e os possíveis fatores de risco envolvidos. Métodos: Em uma primeira etapa foram coletadas 256 amostras de sangue de cães que foram submetidas à reação de imunofluorescência indireta (RIFI) na diluição 1:40. Adicionalmente, 23 amostras positivas na RIFI foram testadas com um teste rápido imunocromatográfico. Em uma segunda etapa, novas amostras de sangue de 18 cães positivos na RIFI na primeira fase do estudo foram coletadas, retestadas pela RIFI $(1: 40$ e 1:80) e, adicionalmente, pela reação em cadeia da polimerase para pesquisa de DNA de Leishmania infantum. Ademais, 16 dessas amostras foram retestadas pelo teste rápido imunocromatográfico. Resultados: Na primeira etapa, 16\% das amostras foram positivas na RIFI (1:40) e apenas três (13\%) foram positivas no teste rápido imunocromatográfico. Na segunda etapa, 12 amostras foram positivas na RIFI na diluição 1:40 e sete também na diluição 1:80. Nenhuma amostra foi positiva na reação em cadeia da polimerase e no teste rápido imunocromatográfico. Sinais clínicos de leishmaniose visceral ocorreram em 4,9\% dos cães positivos. Não houve diferença estatística entre idade, sexo e status clínico dos cães, porém entre seus locais de origem. Conclusões: Os cães domiciliados e semidomiciliados de Garanhuns apresentam anticorpos antileishmania spp, sendo, em sua grande maioria, assintomáticos.

Palavras-chaves: Leishmaniose visceral. Sorologia. Cão. Epidemiologia.

\begin{abstract}
Introduction: Considering the unknown situation regarding canine visceralleishmaniasis in Garanhuns, this study had the aim of investigating occurrences of anti-Leishmania spp antibodies in domesticated and partially domesticated dogs, and the possible risk factors involved. Methods: In the first phase of the study, 256 blood samples were collected from dogs and subjected to the indirect fluorescent antibody test (IFAT) reaction at a dilution of 1:40. Additionally, 23 IFAT-positive samples were tested using an immunochromatographic dipstick test. In the second phase, new blood samples were collected from 18 dogs that were IFAT-positive in the first phase. These animals were retested using IFAT (1:40 and 1:80) and, additionally, by means of the polymerase chain reaction to investigate the Leishmania infantum DNA. Furthermore, 16 of these samples were retested using the immunochromatographic dipstick test. Results: In the first phase of the study, 16\% of the samples were IFAT-positive (1:40) and only three (13\%) were positive in the immunochromatographic dipstick test. In the second phase, 12 samples were IFAT-positive at the dilution of $1: 40$, and seven were also positive at $1: 80$. None of the samples were positive in the polymerase chain reaction testing or in the immunochromatographic dipstick test. Clinical signs suggestive of visceral leishmaniasis were observed in $4.9 \%$ of the IFAT-positive dogs. There were no statistical differences in relation to age, sex or clinical status of the dogs, but there was a difference in relation to place of origin. Conclusions: The domesticated and partially domesticated dogs living in Garanhuns present anti-Leishmania spp antibodies, but are mostly asymptomatic.
\end{abstract}

Key-words: Visceral leishmaniasis. Serology. Dog. Epidemiology.

1. Unidade Acadêmica de Garanhuns, Universidade Federal Rural de Pernambuco, Garanhuns, PE. 2. Instituto Aggeu Magalhães, Fundação Oswaldo Cruz, Recife, PE. 3. Università degli Studi di Bari, Valenzano, Italia. 4. Departamento de Medicina Veterinária, Universidade Federal Rural de Pernambuco, Recife, PE.

Endereço para correspondência: Dra Lucilene Simões-Mattos. Unidade Acadêmica de Garanhuns/ UFRPE. Av. Bom Pastor s/nº, Boa Vista, 55292-270 Garanhuns, PE.

Tel: 55 87 3761-0882, ramal: 244; Telefax: 55 87 3761-0882

e-mail: smattos@uag.ufrpe.br

Recebido para publicação em 11/09/2009

Aceito em 11/01/2010

\section{INTRODUÇÃO}

A leishmaniose visceral (LV) é uma zoonose de grande impacto na saúde pública. No Brasil, a enfermidade encontra-se amplamente difundida, sendo causada pelo protozoário Leishmania (Leishmania) infantum (=Leishmania chagasi), o qual é transmitido de um hospedeiro reservatório ao suscetível pela picada de flebotomíneos, sendo Lutzomyia longipalpis a principal espécie envolvida ${ }^{1}$. Os cães são implicados como os principais reservatórios no ciclo zoonótico de transmissão, particularmente no ambiente doméstico ${ }^{2}$.

No Estado de Pernambuco, a LV humana apresentou considerável expansão geográfica ao longo da década de $90^{3,4}$. Apesar de serhistoricamente endêmica no Sertão pernambucano, a maioria dos casos de LV notificados em humanos na década de 90 provinha da região Agreste ${ }^{4}$. Dantas-Torres e Brandão-Filho ${ }^{4}$ enfatizam que, principalmente entre 1998 e 1999, essa concentração de casos no Agreste pernambucano originou a formação de um cinturão de municípios com LV ao redor de Caruaru. Entretanto, apesar de pertencer a essa região, Garanhuns notificou três casos de LV nos anos de 1995, 1996 e 2001. Porém, sem informações precisas sobre a origem da infecção (F DantasTorres: comunicação pessoal, 2008).

Em se tratando da infecção em cães, a Fundação Nacional da Saúde (FUNASA) estimou que 2,5\% da população canina de Pernambuco seria soropositiva ${ }^{5}$. Entretanto, ao que parece, a realidade é bem diferente, mostrando que, em alguns focos de diferentes municípios, a soroprevalência pode alcançar mais de $50 \%{ }^{6}$. Especificamente em Garanhuns, não há conhecimento sobre ocorrência da LV em cães. Porém, a exemplo do que acontece com humanos em todo estado, o diagnóstico clínico canino também pode estar sendo negligenciado em Garanhuns, por acreditarem ser o município isento de tal zoonose. Um fato importante a ser considerado é que Garanhuns dista em menos de 
$100 \mathrm{~km}$ dos municípios mais próximos pertencentes ao cinturão de LV de Caruaru ${ }^{4}$. Assim, notadamente, Garanhuns reúne condições potenciais para ocorrência da LV humana e canina. Diante do exposto, torna-se então importante conhecer a prevalência de anticorpos antileishmania spp em cães de Garanhuns.

\section{MÉTODOS}

\section{Área de estudo}

O estudo foi conduzido no município de Garanhuns (latitude 0853'25” e longitude 36²9'34”), situado no Agreste Meridional de Pernambuco, no Planalto da Borborema e distante $225 \mathrm{~km}$ de Recife, capital do estado (Figura 1). Possui uma altitude média de $896 \mathrm{~m}$, temperatura média anual de $20^{\circ} \mathrm{C}$ e uma umidade relativa do ar que varia entre 75 a $83 \%{ }^{7}$. O clima predominante na região é o As' que equivale a um clima quente e úmido conforme classificação de Köeppen. A precipitação média é de $1.333,1 \mathrm{~mm}$, sendo os meses mais chuvosos de maio e junho ${ }^{8}$. A maior parte do município, incluindo toda a sua área urbana, encontra-se inserida nos chamados Brejos de Altitude que fazem parte da floresta Atlântica nordestina9 Garanhuns tem um território de $472 \mathrm{~km}^{2}$ e uma população de 124.996 habitantes $^{10}$. Os locais de coleta de sangue dos cães foram determinados através de sorteio aleatório de oito dos 40 postos de vacinação da campanha antirrábica distribuídos pelo município.

\section{População canina e coleta das amostras}

A amostra mínima necessária foi calculada em 234 cães, com base no tamanho da população canina (infinita), soroprevalência esperada (2,5\%), precisão de $2 \%$ e intervalo de confiança de $95 \%$.

A primeira etapa deste trabalho foi realizada no dia 27 de outubro de 2007, quando foram coletadas 256 amostras de sangue de cães domiciliados e semidomiciliados (animais que passam parte do dia fora do domicílio), machos e fêmeas, de diferentes idades e raças, que foram selecionados ao acaso durante a campanha de vacinação antirrábica de Garanhuns. As amostras de sangue foram acondicionadas em tubos individuais sem anticoagulante.
No laboratório, o sangue foi centrifugado a $1.500 \mathrm{~g}$ por 10 minutos. Os soros obtidos foram estocados em freezer a $-20^{\circ} \mathrm{C}$ até serem testados. Dados relativos à idade, sexo, raça, local de origem e sintomatologia de cada animal foram anotados em fichas individuais. Em uma segunda etapa, realizada no período de abril a julho de 2008, foram coletadas 18 amostras de sangue de cães que resultaram positivos na etapa anterior. Nessa etapa, foram coletadas amostras de sangue em tubos com anticoagulante (EDTA 10\%), sendo a coleta realizada no domicílio dos cães, após contato prévio com o proprietário.

\section{Exame clínico dos cães}

Todos os cães da amostra foram examinados para verificar a presença de sinais clínicos sugestivos de LV. Os animais foram classificados como sintomáticos quando apresentavam dois ou mais sinais clínicos sugestivos de LV, tais como perda de peso, dermatite, alopecia, úlceras cutâneas e aumento de linfonodos. Por outro lado, cães com apenas um ou sem qualquer sinal foram considerados assintomáticos.

\section{Diagnóstico sorológico}

Inicialmente, os soros dos cães foram testados por um kit reação de imunofluorescência indireta (RIFI) (IFI-leishmaniose-visceralcanina, Bio-Manguinhos/FIOCRUZ, Rio de Janeiro, Brasil), seguindo estritamente as instruções do fabricante. Consideraram-se positivas as amostras que apresentaram fluorescência no título igual ou superior a 1:40 (ponto de corte). Ademais, 23 amostras escolhidas aleatoriamente entre as positivas na RIFI foram submetidas a um teste rápido imunocromatográfico (Kala-azar Detect, InBios International, Seattle, USA), baseado na reação com um antígeno recombinante (rK39) de Leishmania chagasi (=Leishmania infantum), seguindo as instruções do fabricante. Em uma segunda etapa, foram coletadas novas amostras de parte dos cães $\left(\mathrm{n}^{\mathrm{o}}=18\right)$ que resultaram positivas na RIFI, as quais foram submetidas a uma nova triagem sorológica pela mesma técnica, nas diluições 1:40 e 1:80, e à reação em cadeia da polimerase (PCR) para detecção de DNA de Leishmania infantum. Ademais, 16 dessas amostras foram novamente submetidas ao teste rápido imunocromatográfico.

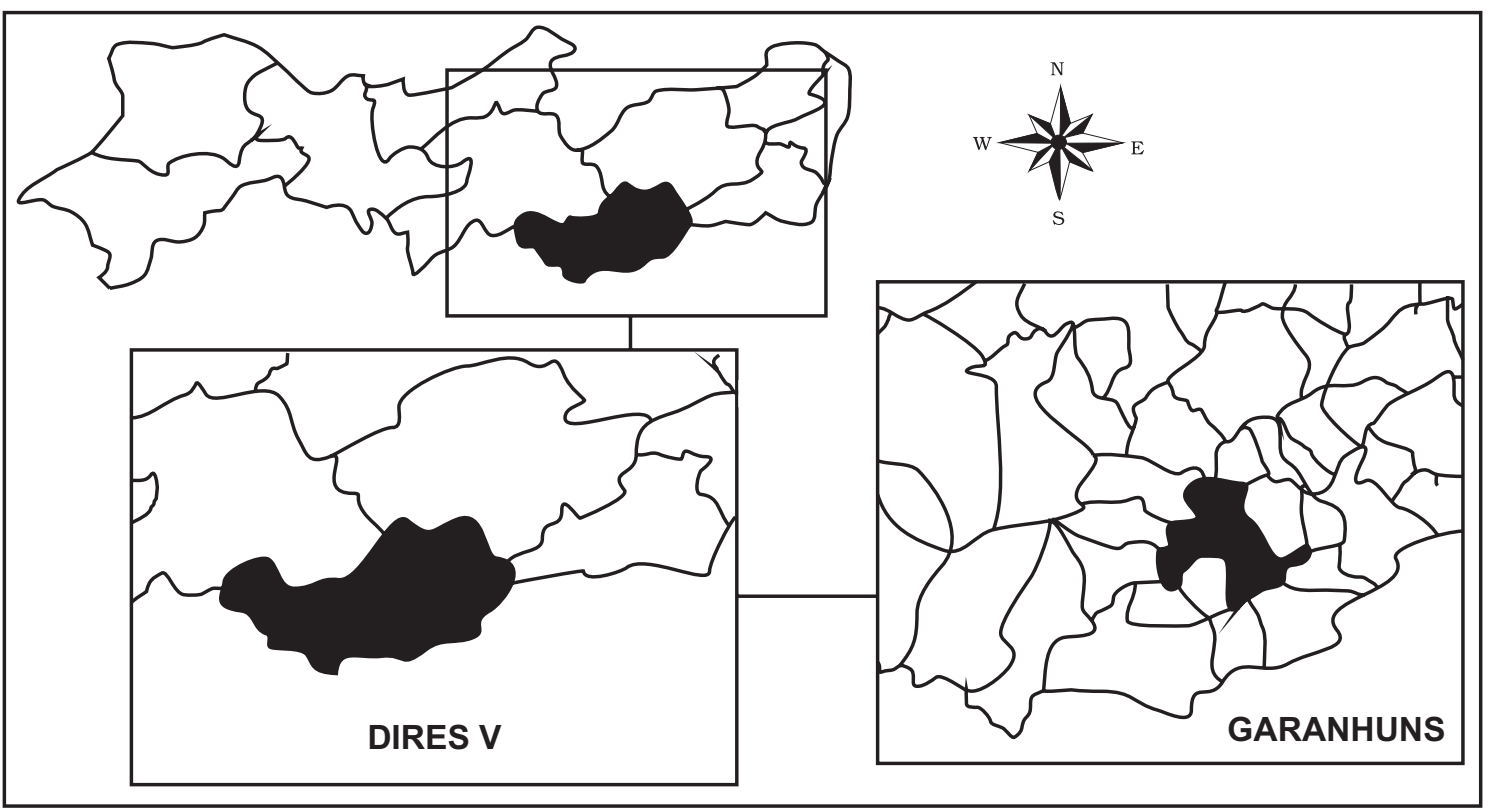

FIGURA 1 - Localização do município de Garanhuns (pertencente à $5^{\text {a }}$ Diretoria Regional de Saúde - DIRES V) no Agreste Meridional pernambucano. 


\section{Diagnóstico molecular}

Primeiramente, foi realizada a extração de DNA de $200 \mu$ l de sangue total dos cães, utilizando um kit comercial (Illustra blood GenomicPrep Mini Spin kit, GE Healthcare, New York, USA), seguindo as recomendações do fabricante. Na PCR, foram utilizados os oligonucleotídeos iniciadores RV1 (senso; 5'- CTTTTCTGGTCCCGCGGGTAGG-3') e RV2 (antissenso; 5'- CCACCTGGCCTATTTTACACCA-3') cujo alvo é a região conservada do DNA do cinetoplasto (kDNA) de Leishmania infantum, produzindo um fragmento de $145 \mathrm{pb}^{11}$. Como controle negativo da PCR foi utilizada água tratada com dietil pirocarbonato (LGC Biotecnologia, Rio de Janeiro, Brasil) e, como controle positivo, utilizou-se DNA purificado de Leishmania chagasi (cepa $\mathrm{MHOM} / \mathrm{BR} / 74 / \mathrm{PP} 75)$. As reações foram realizadas contendo $14 \mu \mathrm{l}$ de água tratada com dietil pirocarbonato, 2,5 $\mu$ l de tampão de reação (10x PCR buffer, Invitrogen, California, USA), $25 \mathrm{mM}$ de $\mathrm{MgCl}_{2}$ (Invitrogen), $2 \mathrm{mM}$ do desoxiribonucleotídeo trifosfato (dNTP) (Invitrogen), 0,5 $\mathrm{ll}(25 \mathrm{pmol} / \mu \mathrm{l})$ de cada oligonucleotídeo iniciador, $5 \mathrm{U} / \mu \mathrm{l}$ de Platinum Taq DNA polymerase (Invitrogen) e $2 \mu \mathrm{l}$ da amostra de DNA, em um volume final de $25 \mu \mathrm{l}$. As amostras foram amplificadas em aparelho termociclador (Mastercycler Gradient, Eppendorf, Hamburg, Germany) em que, após um período inicial de desnaturação de cinco minutos a $94^{\circ} \mathrm{C}$, realizaram-se 35 ciclos (desnaturação, 30 segundos a $94^{\circ} \mathrm{C}$; anelamento, um minuto a $67^{\circ} \mathrm{C}$; síntese, 30 segundos a $72^{\circ} \mathrm{C}$ ), com uma síntese terminal de cinco minutos a $72^{\circ} \mathrm{C}$. Para verificação da amplificação dos fragmentos de DNA, foi utilizado $10 \mu$ l do produto da PCR por eletroforese em gel de agarose a 1,5\%, corado com brometo de etídio, visualizados em transiluminador ultravioleta. Como padrão de peso molecular, utilizou-se DNA do fago lambda digerido com Hind III (New England BioLabs).

\section{Análise dos dados}

A soroprevalência (SP) foi calculada segundo a fórmula: $\mathrm{SP}=\mathrm{n}^{\circ}$ de cães positivos/população coletada $\mathrm{x} 100$. Foi utilizado o teste qui-quadrado $\left(\chi^{2}\right)$ para comparar taxas de prevalência entre sexo, idade, status clínico e local de origem. As diferenças foram consideradas estatisticamente significantes quando o valor de $\mathrm{p} \leq 0,05$. Para realização da análise estatística, adotou-se o programa PopTools, versão 2.7.5. Por fim, calculou-se o erro padrão estimado para cada uma das taxas de prevalência, segundo a fórmula: $P_{\text {estimada }} \pm \sqrt{ } P_{\text {estimada }}\left(1-P_{\text {estimada }}\right) / \mathrm{n}$.

\section{RESULTADOS}

Os dados obtidos em relação à prevalência de anticorpos antileishmania spp dos cães de Garanhuns e os fatores de risco associados encontram-se listados na Tabela 1. De forma geral, a idade dos cães avaliados variou de dois meses a 13 anos, sendo 129 (50,4\%) fêmeas e 127 machos. Das 256 amostras de soros dos cães testadas pela RIFI, 41 foram positivas na diluição $1: 40$, correspondendo a uma prevalência de anticorpos antileishmania spp de $16 \%$. Três (13\%) de 23 amostras positivas pela RIFI, testadas pelo teste rápido imunocromatográfico, foram positivas. Dos 41 cães soropositivos, apenas dois $(4,9 \%)$ foram considerados sintomáticos, ou seja, exibiam dois ou mais sinais clínicos, sendo mais evidentes a perda de peso, alopecia e úlceras cutâneas, principalmente em orelhas e focinho. Dos $39(95,1 \%)$ cães assintomáticos, apenas dois apresentaram um sinal clínico sugestivo de LV.
TABELA 1 - Prevalência de anticorpos antileishmania spp pela reação de imunofluorescência indireta (RIFI) em relação aos fatores de risco dos cães domiciliados e semidomiciliados do município de Garanhuns.

\begin{tabular}{lrrcc}
\hline Fatores de risco & $\mathrm{N}$ & $\mathrm{NP}$ & $\begin{array}{c}\text { Prevalência } \\
(\mathrm{EP} \%)\end{array}$ & p-valor \\
\hline $\begin{array}{l}\text { Idade (anos) } \\
\quad \leq 1\end{array}$ & 61 & 10 & $16,4(11,6-21)$ & \\
$\quad 1$ & 195 & 31 & $15,9(13,2-18,4)$ & 0,914 \\
Sexo & & & & \\
$\quad$ macho & 127 & 21 & $16,5(13,3-19,7)$ & \\
$\quad$ fêmea & 129 & 20 & $15,5(12,3-18,7)$ & 0,956 \\
Status clínico & & & & \\
$\quad$ sintomático & 7 & 2 & $28,6(11,5-45,5)$ & \\
$\quad$ assintomático & 249 & 39 & $15,6(13,3-17,9)$ & 0,692 \\
\hline Total & $\mathbf{2 5 6}$ & $\mathbf{4 1}$ & $\mathbf{1 6}(\mathbf{1 3 , 7}-\mathbf{1 8 , 3})$ & \\
\hline
\end{tabular}

$\mathrm{N}$ : número de animais, NP: número de positivos, EP: erro padrão estimado.

Em relação aos possíveis fatores de risco, dentre os animais positivos, verificou-se que $31(75,6 \%)$ eram maiores de um ano de idade e 21 (51,2\%) eram machos. Entretanto, não houve diferenças estatísticas significativas entre cães jovens e adultos $\left(\chi^{2}=0,011\right.$; p-valor $=0,914)$, tampouco entre os $\operatorname{sexos}(\chi 2=0,002$; p-valor $=0,956) \mathrm{e}$ status clínico $(\chi 2=0,156$; $p$-valor $=0,692)$. Não foram realizadas análises em relação à raça dos cães, pois a maioria deles não possuía raça definida. Foi verificada a ocorrência de anticorpos antileishmania spp em seis (75\%) dos oito postos investigados (Tabela 2), sendo as maiores taxas ocorridas em Aluísio Pinto (30,8\%), seguido por Manoel Xéu (26,7\%) e COHAB II (25\%). No entanto, as taxas de soroprevalência diferiram estatisticamente quando todos os postos de coleta foram comparados $(\chi 2=21,928$; $p$-valor $=0,002)$, havendo também diferenças estatísticas significativas nas taxas observadas entre Heliópolis e Aluísio Pinto $(\chi 2=3,852$; $\mathrm{p}$-valor $=0,049)$; Brasília e Cohab II $(\chi 2=5,170$; $\mathrm{p}$-valor $=$ $0,022)$; Brasília e Manoel Xéu ( $\chi 2=5,115$; p-valor =0,023); Brasília e Aluísio Pinto $(\chi 2=7,573$; $p$-valor=0,005) eAluísio Pinto eVila do Quartel $(\chi 2=3,950 ;$ p-valor $=0,046)$.

Na segunda etapa, 18 dos 41 cães positivos, em que foram repetidas as análises em novas amostras, 12 foram positivos pela RIFI a uma diluição de 1:40, sendo que, sete dessas também reagiram à diluição 1:80. Além disso, todos os cães foram negativos no testes rápido imunocromatográfico, e na pesquisa de kDNA de Leishmania infantum pela PCR em sangue.

TABELA 2 - Prevalência de anticorpos antileishmania spp pela reação de imunofluorescência indireta (RIFI) em soros de cães domiciliados e semidomiciliados coletados em oito postos de saúde do município de Garanhuns.

\begin{tabular}{lcccc}
\hline Posto de coleta & NP/NT & $\begin{array}{c}\text { Prevalência } \\
(\mathrm{EP} \%)\end{array}$ & $\begin{array}{c}\text { Posto de coleta } \\
(\mathrm{DS})\end{array}$ & p-valor \\
\hline Manoel Xéu & $8 / 30$ & $26,7(18,6-34,6)$ & Brasília & 0,023 \\
COHAB II & $11 / 44$ & $25(18,5-31,5)$ & Brasília & 0,022 \\
Aluísio Pinto & $12 / 39$ & $30,8(23,4-38)$ & Brasília & 0,005 \\
Heliópolis & $4 / 39$ & $10,2(5,4-15)$ & Aluísio Pinto & 0,049 \\
Brasília & $2 / 41$ & $4,8(1,5-8,1)$ & - & - \\
Indiano & $4 / 37$ & $10,8(5,7-15,9)$ & - & - \\
Vila do Quartel & $0 / 12$ & 0 & Aluísio Pinto & 0,046 \\
Santo Antônio & $0 / 14$ & 0 & - & - \\
\hline
\end{tabular}

NP: número de positivos, NT: número total de animais coletados, EP: erro padrão estimado; DS: diferença estatística significativa $(p<0,05)$. Obs: constam na tabela apenas os postos que apresentaram diferenças significativas entre os pares. 


\section{DISCUSSÃO}

Os resultados do presente estudo confirmam a suspeita inicial sobre a ocorrência de anticorpos antileishmania spp em cães de Garanhuns, com um número significante de animais positivos pela RIFI. Apesar desta taxa (16\%) ser inferior àquelas encontradas em outros municípios de Pernambuco, como Paulista ${ }^{6}$, é expressiva quando comparada à estimativa média em todo o estado (isto é, $2,5 \%)^{5}$.

A ausência de associação entre presença de anticorpos antileishmania spp e os fatores de risco como a idade e o sexo dos cães corrobora estudos prévios desenvolvidos em uma região endêmica de Minas Gerais ${ }^{12}$. Contudo, é discordante dos achados verificados em regiões litorâneas nordestinas de Pernambuco e Ceará, ${ }^{6,13}$. Diante deste fato, é prudente considerar que a leishmaniose canina seja uma doença de natureza local e que os fatores de risco possam variar de uma região para outra. No entanto, parece bastante evidente que o estilo de vida de cada cão em particular possa favorecer a sua exposição aos vetores e, por conseguinte, a infecção, como é o caso de cães de guarda noturnos ${ }^{14}$.

Curiosamente, os dois postos do município, Aluísio Pinto e Manoel Xeú, em que foram observadas as maiores soroprevalências de anticorpos antileishmania spp exibem graves problemas ambientais, principalmente em relação ao saneamento básico. Além disso, esses bairros estão localizados próximos a resquícios de Mata Atlântica e em algumas residências foram observadas criações de animais de produção. Estas características têm sido especuladas como possíveis fatores de risco para a ocorrência de LV no Nordeste brasileiro ${ }^{6,13}$

De forma similar a outros estudos ${ }^{6,13}$, a grande maioria dos cães soropositivos não apresentou sinais clínicos de LV. Esse fato é bastante relevante, haja vista que os cães aparentemente assintomáticos podem atuar como fonte de infecção aos vetores, potencialmente participando do ciclo zoonótico de transmissão ${ }^{15}$. Os sinais observados nos cães soropositivos desse estudo estão entre os mais frequentemente presentes em inquéritos epidemiológicos realizados no Nordeste do Brasil ${ }^{6,13,16}$. Entretanto, não foram verificados sinais como onicogrifose e conjuntivite, comumente encontrados nesta espécie animal ${ }^{16}$.

Apesar das conhecidas limitações, a RIFI é um dos testes de eleição recomendado pelo Ministério da Saúde em inquéritos sorológicos caninos tendo em vista sua elevada sensibilidade ${ }^{17}$. Por este motivo, essa técnica foi escolhida como de referência no presente trabalho, havendo algumas possíveis explicações para alguns resultados discordantes obtidos com esse teste entre as duas etapas do estudo. Os cães considerados positivos na primeira etapa e negativos na segunda podem ter sofrido influência do tempo decorrido entre as duas coletas. Acedo-Sánchez cols ${ }^{18}$ comentam que nesse período pode haver um aumento da resposta imune celular em detrimento da resposta imune humoral, o que pode resultar em diminuição de anticorpos detectáveis pela RIFI. Além disso, não pode ser excluída a possibilidade de que parte dos cães soropositivos estivesse infectada por outros patógenos, particularmente por outros tripanossomatídeos. Ratificando essa suposição, Costa $\operatorname{cols}^{19}$ observaram que a RIFI realizada com antígenos de Leishmania chagasi em amostras sanguíneas de cães experimentalmente infectados por Leishmania (Viannia) braziliensis e Trypanosoma cruzi apresentou uma alta positividade. Entretanto, é importante ressaltar que a Secretaria de Saúde do município não menciona as localidades urbanas de Garanhuns como de ocorrência endêmica de leishmaniose tegumentar e doença de Chagas em humanos, não havendo casos registrados dessas doenças nas áreas pesquisadas (RMB Leite: comunicação pessoal, 2009).

Em relação ao teste imunocromatográfico, as poucas reações obtidas contra a proteína recombinante rK39 podem estar associadas ao fato deste teste apresentar maior sensibilidade em cães sintomáticos ${ }^{20,21}$. Curiosamente, também em Pernambuco, no município de São Vicente Férrer, alguns cães positivos na RIFI foram negativos no mesmo teste imunocromatográfico (F Dantas-Torres: comunicação pessoal, 2009).

A ausência de DNA de Leishmania infantum nas amostras de sangue sinaliza discordância entre a PCR e a RIFI. Esse resultado demonstra a baixa sensibilidade da PCR neste tipo de amostra, provavelmente devido ao baixo número de parasitos usualmente presentes no sangue ${ }^{22-24}$. Além disso, diferentemente de uma maior sensibilidade da PCR verificada em outros tipos de amostras ${ }^{24-26}$, no sangue há evidências da interferência de inibidores (grupos heme) da $T a q^{26,27}$. É relatada ainda, uma grande variação na sensibilidade da PCR no que se refere ao método de extração de DNA e aos oligonucleotídeos iniciadores utilizados ${ }^{28,29}$. Assim, apesar de Nunes $\mathrm{cols}^{29}$ terem obtido resultados satisfatórios em amostras de sangue de cães, tanto os oligonucleotídeos quanto a proveniência dos animais (regiões endêmicas) diferem da presente pesquisa. Já Gomes cols ${ }^{30}$ obtiveram resultados satisfatórios com os mesmos oligonucleotídeos empregados neste estudo. Porém, em amostras de fígado, baço e linfonodo de cães de áreas endêmicas.

A detecção de anticorpos antileishmania spp em cães de Garanhuns revela uma realidade até então desconhecida no município. Nesse sentido, torna-se imprescindível a realização de novos estudos visando o isolamento e a caracterização das espécies de Leishmania circulantes entre os cães, além da captura e classificação de flebotomíneos no município para identificação dos possíveis vetores. Espera-se que os resultados desde estudo sirvam como um alerta às autoridades de saúde pública em relação à manutenção das ações de vigilância epidemiológica em Garanhuns e em regiões adjacentes.

\section{AGRADECIMENTOS}

À Dra. Carla L. Mendonça da Clínica de Bovinos da UFRPE e à Secretaria de Saúde do Município de Garanhuns, em especial $D_{r}{ }^{a}$. Regia M. B. Leite, Dr. Marcos A. Fernandes e Eliel Duarte pelo amparo logístico. Ademais, aos Professores Antonio R. de S. de Andrade, Paulo J. D. Neto e Kleber R. Santoro da UAG/UFRPE, pela análise estatística.

\section{CONFLITO DE INTERESSE}

Os autores declaram não haver nenhum tipo de conflito de interesse.

\section{SUPORTE FINANCEIRO}

Conselho Nacional de Desenvolvimento Científico e Tecnológico (CNPq) (projeto 410481/2006-8) e PIBIC-CNPq. 


\section{REFERÊNCIAS}

1. Lainson R, Rangel EF. Lutzomyia longipalpis and the eco-epidemiology of American visceral leishmaniasis, with particular reference to Brazil: a review. Mem Inst Oswaldo Cruz 2005; 100:811-827.

2. Dantas-Torres F. The role of dogs as reservoirs of Leishmania parasites, with emphasis on Leishmania (Leishmania) infantum and Leishmania (Viannia) braziliensis. Vet Parasitol 2007; 149:139-146.

3. Dantas-Torres F. Situação atual da epidemiologia da leishmaniose visceral em Pernambuco. Rev Saúde Pública 2006; 40:537-541.

4. Dantas-Torres F, Brandão-Filho SP. Expansão geográfica da leishmaniose viscera no Estado de Pernambuco. Rev Soc Bras Med Trop 2006; 39:352-356.

5. Alexandrino AC. Diagnóstico e controle da leishmaniose visceral: considerações sobre Pernambuco [tese]. [Recife (PE)]: Universidade Federal de Pernambuco; 2001.

6. Dantas-Torres F, Brito MEF, Brandão-Filho SP. Seroepidemiological survey on canine leishmaniasis among dogs from an urban area of Brazil. Vet Parasitol 2006; 140:54-60.

7. Andrade ARS, Paixão FJR, Azevedo CAV, Gouveia JPG, Oliveira Júnior JAS. Estudo do comportamento de períodos secos e chuvosos no município Garanhuns, PE, para fins de planejamento agrícola. Pesquisa Aplicada \& Agrotecnologia 2008; 1:54-61.

8. Mota FS. Agendes MOO. Clima e agricultura no Brasil. Porto Alegre: Sagra; 1986

9. Andrade-Lima D. Present day forest refuges in Northeastern Brazil. In: Prance GT (ed) Biological Diversification in the Tropics. New York: Columbia University Press; 1982, p. 245-254.

10. Instituto Brasileiro de Geografia e Estatística. Contagem populacional 2007 [Internet]. IBGE (BR): Ministério do Planejamento, Orçamento e Gestão [Acessado 17 jun 2009]. Disponível em: http://www.ibge.gov.br/cidadesat/ topwindow.htm? 1 .

11. Le FichouxY, QuarantaJF, AufeuvreJP, LelievreA, MartyP, Suffia I, et al. Occurrence of Leishmania infantum parasitemia in asymptomatic blood donors living in an area of endemicity in southern France. J Clin Microbiol 1999; 37: 1953-1957.

12. França-Silva JC, Costa RT, Siqueira AM, Machado-Coelho GL, Costa CA Mayrink W, et al. Epidemiology of canine visceral leishmaniosis in the endemic area of Montes Claros Municipality, Minas Gerais State, Brazil. Vet Parasitol. 2003; 111:161-173.

13. Rondon FCM, Bevilaqua CML, Franke CR, Barros RS, Oliveira FR, Alcântar AC, et al. Cross-sectional serological study of canine Leishmania infection in Fortaleza, Ceará state, Brazil. Vet Parasitol 2008; 155:24-31.

14. Dantas-Torres F. Canine leishmaniosis in South America. Parasit Vectors 2009; 2(suppl 1):S1

15. Michalsky EM, Rocha MF, da Rocha Lima AC, França-Silva JC, Pires MQ Oliveira FS, et al. Infectivity of seropositive dogs, showing different clinical forms of leishmaniasis, to Lutzomyia longipalpis phlebotomine sand flies. Vet Parasitol 2007; 147:67-76.

16. Almeida MAO, Jesus EEV, Sousa-Atta MLB, Alves LC, Berne MEA, Atta AM. Clinical and serological aspects of visceral leishmaniasis in northeast Brazilian dogs naturally infected with Leishmania chagasi. Vet Parasitol 2005; 127:227232 .

17. Gontijo CMF, Melo MN. Leishmaniose visceral no Brasil: quadro atual, desafios e perspectivas. Rev Bras Epidemiol 2004; 7:338-349.

18. Acedo-Sánchez C, Morillas-Márquez F, Sanchíz-Marín MC, Martín-Sánchez J. Changes in antibody titres against Leishmania infantum in naturally infected dogs in southern Spain. Vet Parasitol 1998; 751-758.

19. Costa CA, Genaro O, Lana M, Magalhães PA, Dias M, Michalick MSM, et al. Leishmaniose visceral canina: avaliação da metodologia sorológica utilizada em inquéritos epidemiológicos. Rev Soc Bras Med Trop 1991; 24:21-25.

20. Lemos EMA, Laurenti MD, Moreira MAB, Reis AB, Giunchetti RC, Raychaudhuri $S$, et al. Canine visceral leishmaniasis: Performance of a rapid diagnostic test (Kalazar DetectTM) in dogs with and without signs of the disease. Acta Trop 2008;107:205-257.
21. Mettler M, Grimm F, Capelli G, Camp H, Deplazes P. Evaluation of enzyme linked immunosorbent assays, an immunofluorescent-antibody test, and two rapid tests (immunochromatographic-dipstick and gel tests) for serological diagnosis of symptomatic and asymptomatic Leishmania infections in dogs. J Clin Microbiol 2005; 43:5515-5519.

22. Fisa R, Rieira C, Gállego M, Manubens J, Portus M. Nested PCR for diagnosis of canine leishmaniasis in peripheral blood, lymph node and bone marrow aspirates. Vet Parasitol 2001; 99:105-111.

23. Lachaud L, Margchergui-Hammami S, Chabbert E, Drereure J, Dedet JP, Bastien P. Comparison of six PCR methods using peripheral blood for detection of canine visceral leishmaniasis. J Clin Microbiol 2002; 40:210-215.

24. Manna L, Vitale F, Reale S, Caracappa S, Pavone LM, Morte RD, et al. Comparison of different tissue sampling for PCR-based diagnosis and follow-up of canine visceral leishmaniosis. Vet Parasitol 2004; 125:251-262.

25. Reale S, Maxia L, Vitale F, Glosriosos NS, Caracappa S, Vesco G. Detection of Leishmania infantum in dogs by PCR with lymph node aspirates and blood. J Clin Microbiol 1999; 37:2931-2935.

26. Reithinger R, Lambson BE, Barker DC, Davies CR. Use of PCR to detect Leishmania (Viannia) spp. in dog blood and bone marrow. J Clin Microbiol 2000; 38:748-751

27. Al-Soud WA, Radstrom P. Capacity of nine thermostable DNA polymerases to mediate DNA amplification in the presence of PCR-inhibiting samples. Appl Environ Microbiol 1998; 64:3748-3753.

28. Ikonomopoulos J, Kokotas S, Gazouli M, Zavras A, Stoitsiou M, Gorgoulis VG. Molecular diagnosis of leishmaniasis in dogs: comparative application of traditional diagnostic methods and the proposed assay on clinical samples. Vet Parasitol 2003; 113:99-113.

29. Nunes C M, Dias AKK, Gottardi FP, Paula HB, Azevedo MAA, Lima VMF. Avaliação da reação em cadeia pela polimerase para diagnóstico da leishmaniose visceral em sangue de cães. Rev Bras Parasitol Vet 2007; 16:5-9.

30. Gomes AHS, Ferreira IMR, Lima MLSR, Cunha EA, Garcia S, Araújo MFL, et al PCRidentification of Leishmania in diagnosis and control of canine leishmaniasis. Vet Parasitol 2007;144:234-241. 